\title{
A MEDIAÇÃO E SUA RELAÇÃO COM A CULTURA DE PAZ E A PACIFICAÇÃO SOCIAL
}

\section{Fernanda Maria Afonso Carneiro ${ }^{1}$}

\section{RESUMO}

O presente artigo apresenta um estudo acerca da cultura de paz que tem como objetivo a pacificação social e coloca a mediação como instrumento auxiliar do Poder Judiciário, demonstrando a utilização e os benefícios desse meio alternativo de solução de conflitos, considerando as suas características específicas. Para tanto, serão mostradas as origens e as motivações dos conflitos sociais, a evolução normativa no Brasil e apresentará a mediação como instrumento de pacificação social. O estudo demonstra que a mediação carrega um novo conceito de democracia, baseado no efetivo acesso à justiça e na conquista da pacificação social.

Palavras-chave: acesso à justiça; conflitos sociais; cultura de paz; democracia; mediação.

\section{MEDIATION AND ITS RELATION WITH THE CULTURE OF PEACE AND SOCIAL PEACE}

\begin{abstract}
This article presents a study about the culture of peace that has as its objective the social peace and puts mediation as auxiliary instrument of the judiciary, demonstrating the using and the benefits this alternative resource of conflict resolution, considering their specific characteristics. It will be shown the origins and motivations of social conflitos, the normative evolution in Brasil and will present the mediation as an instrument of social peace. The study demonstrates that mediation carries a new concept of democracy, based on effective access to justice and the achievement of social peace.
\end{abstract}

Keywords: access to justice; culture of Peace; democracy; mediation; social conflicts.

\section{INTRODUÇÃO}

A solução de controvérsias exclusivamente através do processo jurisdicional, onde cabe ao Estado-julgador estabelecer as regras e impor a solução para o litígio, quase sempre

\footnotetext{
${ }^{1}$ Pós-Doutora em Direito pela Universidade Federal do Ceará, Doutora em Teoria Jurídico-Político Relações Internacionais pela Universidade de Évora, Portugal. Coordenadora do Curso de Direito da Faculdade Novo Tempo de Itapipoca. Conciliadora e Mediadora Judicial do Núcleo Permanente de Métodos Consensuais de Solução de Conflitos do Tribunal de Justiça do Estado do Ceará. Endereço Postal: Rua Vilebaldo Aguiar, 2315 Ap. 501 Torre II - Bairro Cocó - Fortaleza - CE, CEP: 60192-035. Endereço Eletrônico: fernandaafonsoadv@gmail.com.
} 
apresenta um resultado conclusivo que não se reflete em pleno agrado das partes, além de o processo demandar um tempo excessivamente longo e envolver gastos substanciais desnecessários, situações que sempre provocaram queixas e reclamações do cidadão, sobretudo quanto à morosidade do Poder Judiciário.

O principal mecanismo ofertado pelo direito processual ainda é o jurisdicional, no entanto, o atual ordenamento processualístico brasileiro possibilita às partes envolvidas participarem de um diálogo aberto, franco e direto, e eficiente o suficiente a levá-las a encontrar uma solução, utilizando-se dos meios alternativos ou consensuais, ainda que se admita que um ambiente onde ocorram mudanças seja suscetível ao surgimento de dúvidas e questionamentos relacionados aos mecanismos de negociação consensual, mesmo que dotados de garantias constitucionais processuais.

A insatisfação da sociedade com a atuação do Poder Judiciário sinalizou a necessidade de se estabelecer esses mecanismos alternativos no ordenamento jurídico, por serem mais ágeis e mais eficientes na solução dos conflitos de interesse, apesar de o desconforto social não se restringir tão somente aos fatores acima enumerados, ou à reforma da ritualística e à diminuição dos custos financeiros da demanda.

$\mathrm{O}$ cidadão brasileiro anseia que o Judiciário, ao vislumbrar um resultado final que atenda às partes, contribua com a sua atuação na promoção da pacificação social a ser alcançada através de uma mudança cultural relacionada ao papel que deve ser desempenhado por cada um dos envolvidos no conflito.

A importância da plena participação das partes na busca pela solução consensual se reveste de tamanha magnitude e importância, que a expressão "meios alternativos" tem, comumente, sido substituída por outras consideradas mais apropriadas, como "meios adequados" ou "meios amigáveis".

Os meios alternativos ou consensuais, como a arbitragem, a negociação, a conciliação e a mediação, são instrumentos transformadores da sociedade e impulsionadores da cultura da paz, por esse motivo, passaram a exercer papel fundamental na busca pela pacificação social.

É nesse aspecto que a solução de conflitos de interesse através do instituto da mediação possibilita que essa mudança de paradigma possa ocorrer ao permitir e estimular a participação ativa e direta das partes envolvidas. 
Consciente do relevante papel desempenhado pelos instrumentos consensuais, o Conselho Econômico e Social da Organização das Nações Unidas tem recomendado que os seus Estados-membros estimulem a sua prática, caminho igualmente trilhado pela Organização das Nações Unidas para a Educação, a Ciência e a Cultura (Unesco), através da Declaração e Programa de Ação sobre a Cultura de Paz, ao afirmar que "o progresso até o pleno desenvolvimento de uma Cultura de Paz se conquista através de valores, atitudes, comportamentos e estilos de vida voltados ao fomento da paz entre as pessoas, os grupos e as nações" (UNESCO, on-line).

Importante observar que, no Estado do Bem-Estar Social, o direito ao acesso à Justiça passou a ser concebido como um direito material e, nesse aspecto, a Constituição Federal brasileira, no seu artigo $5^{\circ}$, inciso XXXV, o classifica como um direito social básico, garantido a todos os brasileiros, e é a partir dessa premissa básica fundamental que os mecanismos alternativos de solução de conflitos de interesse estão inseridos, destacando-se a mediação como novo paradigma, ao proporcionar que ambas as partes envolvidas no litígio saiam da demanda satisfeitas e considerando-se vencedoras, ao contrário da solução jurisdicional que, quase sempre, fomenta a insatisfação de uma delas.

A mudança transformadora da cultura social torna-se necessária e se manifesta através da adoção de modelos que proporcionam às partes envolvidas no conflito a possibilidade de resolvê-lo através dos mecanismos alternativos, como no caso da mediação, que é o objeto do presente estudo, cujo escopo é demonstrar a importância dessa mudança de paradigma da cultura do litígio para a cultura do diálogo que objetive conduzir a sociedade a alcançar a pacificação social através da aplicação do mecanismo estudado.

Para atingir as finalidades do estudo recorreu-se à pesquisa bibliográfica, desenvolvida fundamentalmente por intermédio de análises em livros, artigos, trabalhos acadêmicos e na legislação pertinente, que tratam dos meios alternativos para solução de conflitos de interesse, especificamente em relação à mediação, utilizando-se o método dedutivo com a finalidade de apresentar os principais aspectos da temática proposta, sendo abordadas as origens e as motivações dos conflitos sociais, o processo evolutivo do conteúdo normativo que disciplina a matéria relacionada ao tema, a partir da Constituição Federal vigente, chegando-se, finalmente, à demonstração da mediação como instrumento capaz de implantar uma cultura de paz e possibilitar a conquista da pacificação social. 


\section{CONFLITOS SOCIAIS: Origens e motivações}

As relações sociais interativas são uma capacidade da pessoa humana que se intensificaram ao longo da história da humanidade em decorrência da necessidade de os indivíduos conviverem em grupos, motivados pelo processo evolutivo ou em razão da própria proteção. Essas relações podem ocorrem de maneira harmônica ou conflituosa. A relação harmônica tem como característica principal a convivência estável entre os indivíduos, pautada pelo respeito ao outro e ao regramento social estabelecido, mas, quando esses pressupostos sociais são desobedecidos, a consequência é o surgimento da oposição de interesses, tornando inevitável o surgimento de uma relação conflituosa (MORAIS; SPLENGER, 2012, p. 17).

O convívio entre os seres humanos, por ser inevitável nas suas distintas matizes, é o principal fato gerador do conflito que surge naturalmente, principalmente porque a busca pela satisfação dos desejos pessoais impacta diretamente nas relações interpessoais, sobretudo quando o interesse individual tenta sobrepor ao interesse coletivo (LIEDKE; SCHIOCCHET, 2012, p. 149).

O conflito, portanto, decorre naturalmente da condição humana, sendo originário de posições antagônicas em relação a fatos e condutas que envolvem expectativas, valores e interesses comuns (VASCONCELOS, 2012, p. 21).

A definição do que seja conflito não é unanimidade entre os doutrinadores e estudiosos do tema e várias são as definições encontradas na literatura, muito embora algumas delas guardem alguma consonância importante.

Robbins (2006, p.78), por exemplo, define que o conflito trata-se de "um processo que se inicia quando um indivíduo ou grupo se sente negativamente afetado por outra pessoa ou grupo", nesse caso, o conflito é compreendido como um entrechoque de ideias ou de interesses que leva ao embate ou à divergência entre fatos ou pessoas.

Esse entrechoque de interesses é o fio condutor utilizado por Vezzulla (2005, p. 19) ao esclarecer que "o conflito consiste em querer assumir posições que entram em oposição com os desejos do outro, que envolve luta pelo poder e que sua expressão pode ser explícita ou se oculta por trás de uma posição ou discurso encobridor".

Morais e Splenger (2012, p. 18) argumentam nessa mesma linha de pensamento que o conflito 
consiste em um enfrentamento entre dois seres ou grupos da mesma espécie, que manifestam, uns a respeito dos outros, uma intenção hostil, geralmente com relação a um direito e, para manter esse direito, afirmá-lo ou restabelecê-lo, muitas vezes lançam mão da violência, o que pode trazer como resultado o aniquilamento de um dos conflitantes.

O conflito, também, pode ser compreendido, de acordo com Luchiari (2012, p. 5), como "um choque de posições divergentes, ou seja, de intenções, condutas diferentes, que aparecem num momento de mudança na vida de uma ou de ambas as partes [...] É o resultado normal das diferenças humanas e da insatisfação de suas necessidades”.

O conflito é visto, portanto, como um fenômeno subjetivo, às vezes, inconsciente, resultado da concorrência de respostas incompatíveis, ou seja, choque de motivos, ou de informações desencontradas, mas que "pode ter efeitos positivos, em certos casos e circunstâncias, como fator motivacional da atividade criadora" e não necessariamente precisa desaguar em litígio, podendo ter uma solução pacífica, desde que "todos os meios possíveis de negociação de controvérsias" sejam direcionados ao diálogo leal, sincero e honesto entre os envolvidos, para que se chegue a um desfecho em que não haja vencidos ou vencedores (MIRANDA, 2012, p. 2).

Essa condição pacificadora se impõe como a decisão mais acertada, considerandose que derrotar litigante oposto, na maioria dos casos, pode não representar, necessariamente, que o problema tenha sido resolvido, ou que a decisão judicial, tomada com base no que os Autos apresentam, seja, realmente, a solução desejada (BENTES, 2012, p. 98).

O conflito nem sempre surge quando uma pessoa é contrariada, ele pode advir, de acordo com Luchiari (2012, p.5), "da evolução inerente à pessoa, que traz um desconforto e tem como consequência o conflito", sendo que, conforme esclarece Vasconcelos (2012, p.19), muitas vezes "o desentendimento pode ser benéfico, algo que propicia a evolução".

O conflito, portanto, decorre da condição de o indivíduo viver em convívio e vincular-se a um contexto relacional que o torna inevitável, mas, essa controvérsia pode ser resolvida de forma justa e pacífica, através de mecanismos que garantem a composição das divergências. Tradicionalmente, porém, em razão da arraigada cultura da sociedade, a composição sempre foi direcionada à ação do Poder Judiciário que aplica a técnica da 
heterocomposição, na qual o juiz, na condição de terceiro imparcial, tem o poder de decidir o conflito (BENTES, 2012, p. 99).

A adoção do sistema de solução dos conflitos sociais, baseada, unicamente, na forma heterocompositiva, direciona-se à relação em que não existe a preocupação com a efetivação dos direitos humanos, de forma coexistencial, ou com o bem-estar das partes envolvidas e isso faz com que a dignidade da pessoa humana fique ainda mais fragilizada, deixando sempre a percepção, muitas vezes injusta, de que a justiça não funciona adequadamente (DA SILVA, 2008, p. 35).

Choques de natureza cultural, étnica, e até mesmo religiosa, que sempre induziram o indivíduo a valer-se do Poder Judiciário, mesmo que sob a égide da cultura da sentença que concede a uma das partes a "vitória" e à outra a "derrota", sem que, para tanto, as alternativas conciliatórias tenham sido devidamente exploradas, são produzidos pelo conflito.

A consequência dessa lógica, muitas vezes perversas, é a multiplicação de processos que emperram o bom funcionamento do Poder Judiciário que se obriga a decidir sobre questões que poderiam ser resolvidas por meio do diálogo entre as partes, contando, para tanto, com o suporte de um intermediário que auxiliaria na consecução do objetivo.

Essa cultura arraigada na sociedade contribui para a deflagração do conflito e o seu próprio andamento está relacionado às características das partes conflitantes, relacionamento prévio, natureza da questão que os originou, ambiente social em que o mesmo ocorre, os espectadores interessados, estratégia empregada pelas partes e consequências para cada participante e partes interessadas (DEUTSCH, 2004, p. 41).

O crescimento do número de conflitos, a tensão nas relações sociais nos mais variados campos do relacionamento humano e institucional e a lentidão da prestação jurisdicional obriga os litigantes a esperar, por um tempo demasiadamente longo, para alcançar a pretensão jurídica, gerando insatisfação e descrédito em relação ao processo judiciário, além de prejuízo para o cidadão.

As garantias constitucionais do ingresso em juízo, do contraditório, do devido processo legal e da celeridade processual têm como fim maior o amplo acesso à justiça, daí porque se torna imprescindível que o processo seja organizado e realizado conforme a regulamentação normativa que são "voltadas a fazer dele um canal de condução à ordem 
jurídica justa", uma vez que seu "escopo magno é a pacificação com justiça." (DINAMARCO, 2005, p. 375).

A segurança jurídica e a celeridade processual devem, necessariamente, caminhar em uníssono, no entanto, entraves e carência de recursos humanos, técnicos e materiais, fizeram com que essa possibilidade ficasse cada vez mais distante da realidade, o que tornou imperioso que o Poder Público adotasse medidas urgentes e necessárias, para sanar a deficiência na prestação da assistência jurisdicional aos cidadãos (AMARAL, 2009, p. 23 - 24).

Refletir como e por que surgem os conflitos importa remeter-se à insatisfação do indivíduo, quando os interesses de um ou de outro divergem, e se busca satisfazer as pretensões, não aceitando perda, e dessa insatisfação origina-se o conflito interpessoal (DA SILVA, 2008, p. 32).

É a partir dessa premissa que a adoção de políticas públicas que eliminem entraves que dificultam o pleno acesso à justiça e encontrem a "solução adequada aos conflitos de interesse, pela participação decisiva" das partes, torna-se essencial quando se buscar "um resultado que satisfaça seus interesses, o que preservará o relacionamento delas, propiciando a justiça coexistencial" (WATANABE, 2011, p. 4).

Nesse contexto, a sociedade brasileira, através dos segmentos civis organizados e da atuação dos seus representantes, introduziu, no vigente texto constitucional, importantes dispositivos que privilegiam os direitos fundamentais e a dignidade humana e fortalecem o papel a ser desempenhado pelo Poder Judiciário. Dentro dessa mesma seara, os legisladores aprovaram legislação específica que torna mais fácil o acesso à justiça e estimula a solução dos conflitos de interesse fora do processo judicial (RUIZ; NOGUEIRA, 2012, p. 118).

\section{A EVOLUÇÃO NORMATIVA}

A Constituição Federal, no seu art. 99, assegura ao Judiciário o poder soberano e a autonomia administrativa e financeira, enquanto que o art. 96, no inciso I, letra "a", nos mesmos termos, concede competência aos tribunais para "eleger seus órgãos diretivos e elaborar seus regimentos internos", observando normas de processo e garantias processuais das partes, além de dispor sobre competência e funcionamento dos órgãos jurisdicionais e administrativos (BRASIL, 2017). 
$\mathrm{O}$ direito ao amplo acesso à justiça trata-se de um direito fundamental garantido pelo inciso XXXV, do art. $5^{\circ}$ da Constituição ao manifestar que "a Lei não excluirá da apreciação do Poder Judiciário lesão ou ameaça a direito", possibilitando à pessoa vítima de violência ou de ameaça o seu direito a acessar o Judiciário, podendo ser considerado como base dos direitos humanos individuais (CAPPELLETTI; GARTH, 2002, p. 12).

Ao disciplinar os fundamentos da República Federativa do Brasil, que se constitui em Estado Democrático de Direito, a Constituição, no art. $1^{\circ}$ Inciso III, traz a dignidade da pessoa humana como um desses elementos e prevê, no art. 98, a criação de juizados especiais cíveis e criminais, no âmbito de atuação da União e seus entes membros (Estados e Distrito Federal), atribuindo-lhes legítima competência para a solução pacífica de conflitos de interesse, tema, posteriormente, regulamentado pela Lei no 9.099/1995 (BRASIL, 2017).

O sistema de juizados especiais, organizado como estrutura à parte do Judiciário, é dotado de proposta alternativa de tutela de justiça, tratando-se, desta forma, de modelo considerado popular e participativo de justiça, ainda que o seu principal intuito não seja solucionar definitivamente os problemas crônicos do Poder Judiciário, mas resolver, com maior e menor custo e rapidez, litígios de menor complexidade, tendo por base os seus princípios, elencados no art. $2^{\mathrm{o}}$ da lei, que conduzem a amplo acesso ao Judiciário e à busca do entendimento entre as partes, sem violação das garantias constitucionais do contraditório e da ampla defesa (CUNHA JÚNIOR, 1988, p. 662).

Os juizados especiais, portanto, intentam solucionar litigiosidade, baseando-se na simplicidade e na celeridade dos processos, sob o critério da oralidade, podendo o autor da causa ajuizar diretamente, sem assistência de advogado, salvo em momento recursal, configurando-se, dessa forma, como um sistema ágil e simplificado de distribuição da Justiça, independentemente da condição econômica do indivíduo (CHIMENTI, 2004, p. 5).

De acordo com a lição de Carneiro (1999, p. 106-107):

É importante destacar aqui a preocupação do legislador com a igualdade material, a igualdade de armas, visando a um adequado equilíbrio técnico entre as partes durante o processo. Assim, não bastará que o juiz alerte a parte sobre a necessidade de ser assistido por advogado, ou mesmo nomeie um defensor dativo para tanto, é preciso antes de tudo que o desempenho do representante seja razoavelmente valioso, de sorte a permitir o equilíbrio preconizado pela lei. 
Os princípios da economia processual, da oralidade, da simplicidade e da celeridade observados e a determinação pela busca do entendimento entre as partes atenderam à necessidade jurídica de concluir as ações de forma apropriada e célere. A valoração dos princípios da Lei $n^{\circ}$ 9.099/1995, em detrimento do formalismo que vinha dominando a praxe jurídica, reverteu-se em benefício da coletividade, tendo como maior benefício a possibilidade da solução do conflito de interesse pelo entendimento direto entre as partes, evitando, com isso, o início do litígio por via judicial (CHIMENTI, 2004, p. 8).

Os juizados especiais foram pensados e incluídos no ordenamento jurídico nacional com o objetivo de possibilitar que as pessoas possam, de maneira menos burocrática e demorada, buscar a proteção de interesses individuais, considerados de menor complexidade e expressão econômica, de forma célere e justa, e funcionam como principal celeiro conciliatório e mediador (SANTOS, 2007, p. 47).

A Resolução $n^{\circ}$ 125/2010 do Conselho Nacional de Justiça (CNJ) instituiu a Política Judiciária Nacional, voltada ao tratamento do conflito, com o objetivo precípuo de assegurar a todos os cidadãos, indistintamente, o direito de acesso aos mecanismos consensuais adequados e atribuiu competência ao Conselho Nacional de Justiça para organizar programa com o objetivo de promover ações de incentivo à autocomposição de litígios e à pacificação social através da conciliação e da mediação, a ser implementado com a participação de rede constituída por todos os órgãos do Poder Judiciário e entidades públicas e privadas parceiras, inclusive universidades e instituições de ensino ( $\mathrm{CNJ}$, on-line).

A resolução citada, também, criou os Núcleos Permanentes de Métodos Consensuais de Solução de Conflitos (NUPEMECS), no âmbito dos Tribunais de Justiça, aos quais atribui competência para desenvolvimento e planejamento da política consensual de solução de conflitos, bem como a de instalar, nos Juízos, Varas e Juizados, Centros Judiciários de Solução de Conflitos e Cidadania (CEJUSCS), responsáveis pela realização de sessões de conciliação e de mediação (CNJ, on-line).

O governo federal, através do Ministério da Justiça, criou a Escola Nacional de Mediação e Conciliação (ENAM), sediada em Brasília, com atuação nos Estados pelos Núcleos Estaduais, com o objetivo de capacitar estudantes e profissionais do direito, professores e agentes de mediação comunitária, além de servidores do próprio Ministério da 
Justiça e integrantes de órgãos, entidades e instituições para o exercício de atividades ligadas à solução de conflitos de interesse (CNJ, on-line)

A Lei $n^{\circ} 13.105 / 2015$, que instituiu o atual Código de Processo Civil brasileiro, determina, no art. 165, a instalação, pelos Tribunais de Justiça, de Centros Judiciários de Solução Consensual de Conflitos (CEJUSCS), com o objetivo de realizar sessões e audiências de conciliação e mediação, além do "desenvolvimento de programas destinados a auxiliar, orientar e estimular a autocomposição", e, em artigos subsequentes (do 166 ao 173), trata da implantação dos mecanismos da conciliação e da mediação, bem como do papel a ser exercido pelos respectivos conciliadores e mediadores (BRASIL, 2016).

A Lei $n^{\circ} 13.140$, de 26 de Junho de 2015, dispõe sobre a mediação entre particulares como meio de solução de controvérsias e a autocomposição de conflitos no âmbito da Administração Pública. O art. 1 ${ }^{\text {a }}$, parágrafo único, da lei, estabelece, ao conceituar o instituto ao qual faz referência direta, que "considera-se mediação a atividade técnica exercida por terceiro imparcial sem poder decisório, que, escolhido ou aceito pelas partes, as auxilia e estimula a identificar ou desenvolver soluções consensuais para a controvérsia" (CNJ, on-line).

O Provimento $n^{\mathbf{o}}$ 2.348/2016, do Conselho Superior da Magistratura, permitiu a criação de Câmaras Privadas de Conciliação e Mediação, dotadas de personalidade jurídica definida, com ou sem fins lucrativos. As câmaras privadas não são órgãos julgadores, apenas ofertam serviços alternativos para a resolução de conflitos de interesse e possuem os mesmos direitos e deveres dos mediadores e conciliadores que atuam nos centros públicos. Os Centros Judiciários de Solução de Conflitos e Cidadania (CEJUSCS), de acordo com o disposto no Provimento CSM n 2.348/2016, no seu art. 33, são responsáveis pela capacitação e cadastramento de conciliadores e mediadores para atuação nas Câmaras Privadas de Conciliação e Mediação (CNJ, on-line).

Verifica-se, portanto, tendo por base o extenso cabedal normativo acima explicitado, que a sociedade brasileira encontrou, nos mecanismos alternativos ou consensuais de solução dos conflitos de interesse, o caminho a ser percorrido para implantar uma cultura de paz no país e, dessa forma, alcançar a pacificação social. Nesse sentido, a mediação se impõe como um importante e eficaz instrumento de solução de conflitos de interesse, ao possibilitar o diálogo entre as partes e a solução consensual, além de ter como principal objetivo a conquista da paz social. 


\section{MEDIAÇÃO E PACIFICAÇÃO SOCIAL}

Os mecanismos alternativos ou consensuais estão inseridos na terceira onda renovatória, que apresenta um "novo enfoque de acesso à Justiça", e possibilitaram a adoção de reformas estruturais no Poder Judiciário e no sistema processual, tornando a Justiça mais acessível e adequada à sociedade contemporânea (CAPPELLETTI; GARTH, 2002, p.71).

Implementados com grande sucesso em vários países, como procedimentos complementares ao processo judicial tradicional, esses mecanismos, além de serem mais democráticos, são mais rápidos, mais baratos e mais eficientes em muitos casos, razão porque têm sua aplicação cada vez mais estimulada e empregada, se constituindo no primeiro estágio para a solução de uma demanda por meios pacíficos (WATANABE, 2005, p. 49).

Entre estes institutos, a mediação se destaca por ser um mecanismo diferente do modelo tradicional de justiça, pois, solucionar conflitos vai muito além da prolação da sentença, depende de uma visão integral da questão e dos envolvidos; da possibilidade de intervenção social efetiva para se chegar à pacificação social; e da real possibilidade de se alcançar os objetivos pretendidos (WATANABE, 2005, p. 50).

A pacificação social deduz a ideia de propiciar a solução para um determinado conflito de interesse de acordo com a legislação e a vontade das partes, no entanto, o seu objetivo vai além da mera resolução consensual, porque envolve o estado de espírito humano, além de abarcar aspectos jurídicos, psicológicos e sociológicos, muito embora alcançá-la ainda seja um desafio que pode vir a ser atingido através do mecanismo da mediação (TARTUCE, 2015, p. 222).

O autor acima citado (2015, p. 226) destaca, ainda, que "em razão da metodologia que lhe é peculiar, a mediação vai mais longe que outros meios de composição de conflitos ao buscar as causas da controvérsia para tentar sanar o sofrimento humano", uma vez que o mecanismo tem a capacidade de possibilitar a resolução de conflitos cotidianos concretos e de aproximar o cidadão da justiça e do direito social (BACELLAR, 1999, p. 124).

Azevedo (2009, p. 20) compartilha do pensamento do autor acima ao mencionar que a “mediação permite a solução do conflito de forma construtiva, fortalece as relações sociais, promove os relacionamentos cooperativos e explora estratégias que possam prevenir ou resolver futuras controvérsias". 
A participação direta das partes nas negociações é destacada pelos estudiosos do tema como um dos mais fortes preceitos da mediação, conforme esclarece Tartuce (2015, p. 211) ao expor que o mecanismo "permite que o indivíduo decida os rumos da controvérsia, resgate sua responsabilidade e protagonize uma saída consensual para o conflito, o que o inclui como importante ator na configuração da solução da lide...”, e destaca, ainda, fortalecendo o seu argumento que "a mediação, enquanto método que concebe o mediando como protagonista de suas próprias decisões e responsável por seu próprio destino, está fundamentada na dignidade humana em seu sentido mais amplo" (TARTUCE, 2015, p. 211).

De acordo com os ensinamentos de vários doutrinadores, a mediação é definida como sendo um processo, nesse sentido, Azevedo (2002, p. 160) destaca que “a mediação é o processo pelo qual uma terceira parte auxilia duas ou mais partes a alcançarem soluções próprias acerca de uma ou mais questões, ou seja, a mediação é simplesmente uma negociação assistida", de onde se observa que a imparcialidade dessa terceira pessoa, chamada mediador, é essencial para o sucesso do processo de mediação.

A participação de um terceiro no processo, denominado mediador, que orienta e auxilia as partes a chegarem ao consenso, sem, contudo, interferir na decisão, é o que torna a mediação como um dos instrumentos mais democráticos e participativos entre os mecanismos consensuais de solução de conflitos de interesse.

A função do mediador é a de agente facilitador de uma mudança de percepção em relação ao conflito, cuja intervenção no processo leve as partes a refletirem em torno de uma convivência harmoniosa e de respeito às diferenças, levando-as a contribuírem para a promoção da pacificação social que passa a compor aspecto primordial e relevante através dos meios alternativos de solução de conflitos de interesse, instrumentos integrados ao próprio sistema processual para atingir o objetivo (LUCHIARI, 2012, p. 62).

O mediador deve atuar como condutor da sessão, cabendo a ele ajudar as partes a encontrar uma solução para o conflito que seja do agrado de ambas, razão porque a mediação é vista como "um sistema de negociação assistida mediante o qual as partes envolvidas em um conflito tentam resolvê-lo por si mesma, com a ajuda de um terceiro imparcial..." (SILVA, 2012, p. 155).

De acordo com Vezulla (2003, p. 117), "se o objetivo da mediação consiste em conseguir que os clientes possam exercer a autodeterminação, o mediador deve cumprir a 
função emancipadora de conduzir e acompanhar os mediados em seus processos catárticos de libertar-se do medo e da piedade".

Nesse sentido, Azevedo (2002, p.163) define mediação como "um conjunto de atos coordenados, lógica e cronologicamente, visando atingir escopos pré-estabelecidos, possuindo fases e pressupondo a realização da prática de determinados atos para se atingirem, com legitimidade, fins esperados".

No entanto, para Bacellar (1999, p. 122), a "mediação se insere em um modelo consensual (ganha/ganha) para as controvérsias. [...] As técnicas de mediação buscam solução pacífica para as controvérsias e podem ser aplicadas dentro e fora do Poder Judiciário."

Verifica-se, dessa forma, que a mediação alcança a qualidade de agente propulsor de distintas melhorias e vantagens, dentre as quais podem ser citadas a redução do desgaste emocional, do custo financeiro da demanda, elaboração de soluções apropriadas às reais necessidades das partes, a satisfação dos envolvidos, mais celeridade na solução de conflitos pela própria desburocratização do processo, uma vez que impera a informalidade nas sessões, a possibilidade da solução do litígio por profissional escolhido pelos litigantes, conforme a natureza da questão e a garantia de privacidade e sigilo do que ocorre nas sessões (PEREIRA, 2015, p. 05).

A mediação, portanto, viabiliza o exercício da democracia participativa, a responsabilidade e a colaboração das partes, além de lhes proporcionar autonomia na solução do conflito, cumprindo, dessa forma, o fundamento político da jurisdição ao permitir a participação popular na administração da Justiça. O desenvolvimento dessa perspectiva favorece o senso de colaboração entre as partes, além de propiciar o desenvolvimento do sentido pedagógico, ao possibilitar que o cidadão possa aprender a lidar com o conflito e buscar, através dos seus próprios meios, sua adequada superação (SILVA, 2012, p. 184).

Nesse contexto, a construção do acordo através da participação das partes reveste-se em aspecto fundamental a ser considerado no processo de mediação, conforme esclarece Warat (2001, p. 199), ao observar que "[...] o acordo decorrente de uma mediação, satisfaz, em melhores condições, as necessidades e os desejos das partes, já que estas podem reclamar o que verdadeiramente precisam, e não o que a lei lhes reconheceria", sendo, plausível estabelecer a completude da pacificação humana oferecida pela mediação, visto que essa atinge pontos que, normalmente, não são alcançados por outros meios resolutivos, conforme 
esclarece Sales (2003, p. 33), ao apontar a "eficiência pacificadora da mediação pela capacidade de resolução real bem como pela prevenção".

É nesse aspecto que a participação das partes, como principal fundamento social das vias consensuais percorridas pelo mecanismo da mediação, favorece o desenvolvimento de uma cultura da paz e possibilita a conquista da tão almejada pacificação social que nem sempre é alcançada pela sentença, a qual se limita a ditar a regra para o caso concreto, nem sempre aceita de bom grado pela parte vencida que contra ela costuma insurgir-se, por limitarse a impor a solução sem possibilidade de pacificar a lide sociológica (GRINOVER, 2007, p. 03-04).

Isso porque, na mediação a investigação tem como foco principal os interesses que são convergentes e os possíveis valores e crenças que propiciam o litígio, sem procurar modificar a relação entre as partes, exceto com o objetivo de buscar resolver o conflito de interesse, considerando, para tanto, os valores e preconizando o entendimento do justo para o deslinde (SILVA, 2012, p. 140).

O objetivo maior da mediação, portanto, não é tão somente se chegar a um acordo, mas possibilitar a transformação dos cidadãos e dos seus sentimentos já que o mecanismo trata-se de "um trabalho de reconstrução simbólica do conflito, que é capaz de promover uma transformação no conflito por meio de uma reinterpretação que, conferindo novas significações à relação conflituosa, recrie a possiblidade de uma convivência harmônica das diferenças" (WARAT, 2001, p. 31).

Assim sendo, a verdadeira Justiça só é alcançada mediante a solução das demandas através de um consenso que seja capaz de solucionar não somente a lide em discussão, mas tudo que envolva o relacionamento entre as partes e, nesse aspecto, com a utilização do mecanismo da mediação, o Estado se aproxima de uma clara conquista da pacificação social e da harmonia entre os cidadãos (PORTUGAL, 1999, p. 10).

A mediação tem em vista o acordo pela liberdade da escolha e consensualidade, possibilitando, dessa maneira, a continuidade de relacionamentos futuros por meio da prevenção de possíveis controvérsias, se constituindo, dessa forma, na alternativa mais significativa na busca da almejada celeridade e efetividade da solução dos conflitos, quer sejam elas judiciais ou extrajudiciais. Mais que um mecanismo para combater a morosidade 
do Poder Judiciário, o objetivo primordial da mediação é oferecer às partes a possibilidade de solucionar seus conflitos de uma maneira materializada pela celeridade, eficiência e validade

judicial, contribuindo, decisivamente, para a implantação de uma cultura da paz na sociedade e a conquista da tão almejada pacificação social.

\section{CONSIDERAÇÕES FINAIS}

As reformas e atualizações promovidas no Código de Processo Civil brasileiro representaram um importante marco no cenário jurídico, ao apresentar uma nova realidade do Judiciário, trazendo em seu bojo os preceitos expressos na Carta Magna e aliando-se às diretrizes estabelecidas pelo Conselho Nacional de Justiça que, através da Resolução $n^{\circ} 125$ de novembro de 2010, instituiu a criação de núcleos e centros de solução de conflitos em todos os tribunais brasileiros.

É inegável que o Poder Judiciário brasileiro tem procurado atingir a eficiência na promoção e proteção dos interesses coletivos e individuais dos cidadãos e, nesse sentido, tem difundido a prática da solução dos conflitos de interesse através da utilização dos mecanismos consensuais, como a mediação, tão necessária para o desenvolvimento social, bem como o seu amplo acesso, por trata-se de um direito fundamental e um eficaz meio para reduzir as desigualdades sociais e atender ao ideal de promoção da dignidade da pessoa humana ( $C N J$, on-line).

A atualização do ordenamento processualístico brasileiro configura-se, dessa forma, como uma mudança de paradigma no mundo jurídico visto que viabiliza o exercício da democracia participativa, fortalece o pleno exercício da cidadania e provoca as partes envolvidas em conflito a agirem com responsabilidade e de maneira colaborativa na solução da controvérsia.

O novo cenário que se estabeleceu no Judiciário foi uma resposta às pressões exercidas pelo tecido social que tem, cada vez mais, exigido atendimento e resultados eficientes e de melhor qualidade, provocando, dessa forma, a necessidade de se introduzir mudanças que venham a superar gargalos e propiciar a criação de uma nova dinâmica entre as relações sociais, com ou sem interferência do Estado-Julgador, o que representa uma quebra de paradigma que traz, no sentido, a presença do novo, por representar a possibilidade de 
alteração de pressupostos básicos, a reformulação da forma de agir e a adoção de um novo conjunto de regras.

Os diplomas legais estudados permitem acelerar a quebra desse paradigma ao conscientizar e motivar a sociedade quanto à possibilidade de utilização de instrumentos que expressam novas possibilidades alternativas para a solução de demandas, alicerçados no entendimento e na concessão mútua por parte dos envolvidos, permitindo-lhes, com o auxílio da estrutura jurídica estatal, que atua no processo como agente facilitador, despido da sua condição impositiva em relação a uma decisão, chegar a um entendimento que leve à solução da controvérsia estabelecida entre as partes.

Esse novo cenário está em consonância com a nova concepção de acesso à justiça, no qual a estrutura do Judiciário se apta não só para oferecer uma decisão lastreada na prolação de sentença, mas, também, com o objetivo de promover os meios necessários à construção de uma cultura de paz, fundamento imprescindível quando se pretende conquistar a pacificação social.

O desenvolvimento do presente estudo, portanto, centrou-se numa análise conceitual e normativa sobre os mecanismos alternativos ou consensuais de solução de conflitos de interesse, com foco no instituto da mediação, por tratar-se da forma consensual com maior arcabouço normativo e técnico, além de servir como instrumento de alteração cultural, instigando a participação social, a democratização da justiça, e assegurando a autodeterminação e a responsabilização adequada das partes, além de restaurar as relações sociais, possibilitar o fim do conflito e prevenir novas contendas.

A mediação como meio alternativo ou consensual de solução de conflitos de interesse representa um importante instrumento auxiliar do Judiciário, na medida em que sua finalidade é a busca do consenso por meio de decisões céleres e justas que satisfaçam as pretensões das partes, por essa razão, são evidentes os seus benefícios para a sociedade brasileira que tem ao seu dispor um processo mais adequado e célere que garante a participação social devida na solução dos próprios conflitos, difundindo a cultura de paz e assegurando o alcance da pacificação social de maneira eficiente e duradoura.

\section{REFERÊNCIAS}

Revista de Formas Consensuais de Solução de Conflitos | e-ISSN: 2525-9679 | Belém | v. 5 | n. 2 | p. 01 - 19 | Jul/Dez. 2019. 
AMARAL, Márcia Terezinha Gomes. O direito de acesso à justiça e a mediação. São Paulo: Lúmen Juris, 2009.

AZEVEDO, André Gomma de. Autocomposição e processos construtivos: uma breve análise de projetos-piloto na mediação forense e alguns de seus resultados. In: AZEVEDO, André Gomma de (Org). Estudos em arbitragem, mediação e negociação. Brasília: Brasília Jurídica, v. 3, 2002.

AZEVEDO, André Gomma de. Fatores de efetividade de processos de resolução de disputas: uma análise sob a perspectiva construtivista. In: CASELLA, P.; SOUZA, L. (Coord.). Mediação de conflitos - novo paradigma de acesso à justiça. Belo Horizonte: Ed. Fórum, 2009.

BACELLAR, Roberto Portugal. A mediação no contexto dos modelos consensuais de resolução de conflitos. São Paulo: Revista de Processo, ano 24, n. 95, 1999.

BENTES, Hilda Helena Soares. Direitos humanos e mediação. In: BENTES, Hilda Helena Soares; SALLES, Sérgio de Souza (Orgs.). Mediação e educação em direitos humanos. Rio de Janeiro: Lumen Juris, 2012.

BRASIL. Código de Processo Civil. São Paulo: Saraiva, 2016.

. Constituição da República Federativa do Brasil. São Paulo: Saraiva, 2017.

CAPPELlETTI, Mauro; GARTH, Bryant. Acesso à justiça. Tradução de Ellen Gracie Northfleet. Porto Alegre: Sérgio Fabris Editor, 2002.

CARNEIRO, Paulo Cezar Pinheiro. Acesso à justiça: juizados especiais cíveis e ação civil pública. Rio de Janeiro: Forense, 1999.

CHIMENTI, Ricardo Cunha. Teoria e prática dos juizados especiais cíveis estaduais e federais: Lei 9.099/95 e 10.259/2001. 7. ed. São Paulo: Saraiva, 2004.

CNJ - CONSELHO NACIONAL DE JUSTIÇA. Disponível em: www.cnj.jus.br. Acesso em: 15 jul. 2019.

CUNHA JÚNIOR, Dirley da. Curso de Direito Constitucional. 2. ed. Bahia: Podium, 2008.

DA SILVA, João Roberto. Arbitragem. 2. ed. São Paulo: Malheiros, 2008.

DEUTSCH, Morton. A resolução do conflito. In: AZEVEDO, André Gomma. Estudos em arbitragem, mediação e negociação. Brasília. 2004. Disponível em: https://edisciplinas.usp.br/mod/resource/view.php?id=2257166. Acesso em: 17 jul. 2019.

Revista de Formas Consensuais de Solução de Conflitos | e-ISSN: 2525-9679 | Belém | v. 5 | n. 2 | p. 01 - 19 | Jul/Dez. 2019. 
DINAMARCO, Cândido Rangel. A instrumentalidade do processo. 12. ed. São Paulo: Malheiros, 2005.

GRINOVER, Ada Pelegrini. Os fundamentos da Justiça Conciliativa. In: GRINOVER, Ada Pelegrini; KAZUO, Watanabe; LAGRASTA NETO, Caetano. Mediação e Gerenciamento do Processo: revolução na prestação jurisdicional. São Paulo: Atlas, 2007.

LIEDKE, Mônica Souza; SCHIOCCHET, Taysa. O futuro dos núcleos de práticas jurídicas nas universidades brasileiras. In: BENTES, Hilda Helena Soares; SALLES, Sérgio de Souza (Orgs.). Mediação e educação em direitos humanos. Rio de Janeiro: Lumen Juris, 2012.

LUCHIARI, Valéria Ferioli Lagrasta. Mediação judicial: análise da realidade brasileira origem e evolução até a Resolução n. 125, do Conselho Nacional de Justiça. Rio de Janeiro: Forense, 2012.

MIRANDA, Maria Bernadete. Aspectos relevantes do instituto da mediação no mundo e no Brasil. São Paulo: Revista Virtual de Direito, v. 6, n. 2, 2012. Disponível em: http://www.direitobrasil.adv.br/arquivospdf/revista/revistav62/artigos/be2.pdf. Acesso em: 20 jul. 2019.

MORAIS, José Luis Bolzan; SPLENGER, Fabiana Marion. Mediação e arbitragem: alternativas à jurisdição. Porto Alegre: Livraria do Advogado, 2012.

PEREIRA, Clóvis Brasil. Conciliação e Mediação no Novo CPC. Disponível em: http://www.prolegis.com.br/conciliacao-e-mediacao-no-novo-cpc-no-03/. Acesso em: 01 jul. 2019.

ROBBINS, Stephan P. Comportamento organizacional. São Paulo: Prentice Hall, 2006.

RUIZ, Ivan Aparecido; NOGUEIRA, Luís Fernando. A mediação como instrumento de efetivação do direito humano e fundamental do acesso à justiça em uma nova face: o ser humano como seu construtor e protagonista. In: BENTES, Hilda Helena Soares; SALLES, Sérgio de Souza (Orgs.). Mediação e educação em direitos humanos. Rio de Janeiro: Lumen Juris, 2012.

SALES, Lília Maia de Morais. Justiça e mediação de conflitos. Belo Horizonte: Del Rey, 2003.

SANTOS, Boaventura de Sousa. Para uma revolução democrática da justiça. 3. ed. São Paulo: Cortez, 2007. 
SILVA, Érica Barbosa e. A efetividade da prestação jurisdicional civil a partir da conciliação. 2012. Tese (Doutorado em Direito) - Faculdade de Direito, Universidade de São Paulo, São Paulo, 2012. Disponível em: http://www.teses.usp.br/teses/disponiveis/2/2137/tde22042013-084020/pt-br.php. Acesso em: 08 jul. 2019.

TARTUCE, Fernanda. Mediação nos conflitos civis. 2. ed. Rio de Janeiro: Forense; São Paulo: Método, 2015.

UNESCO - ORGANIZAÇÃO DAS NAÇÕES UNIDAS PARA A EDUCAÇÃO, A CIÊNCIA E A CULTURA. Declaração e programa de ação sobre uma cultura de paz. Disponível em: <www.comitepaz.org.br>. Acesso em: 13 jul. 2019.

VASCONCELOS, Carlos Eduardo de. Mediação de Conflitos e práticas restaurativas. 2. ed. Rio de Janeiro: Forense; São Paulo: Método, 2012.

VEZZULLA, Juan Carlos. Mediação: teoria e prática: guia para utilizadores e profissionais. 2. ed. Rio de Janeiro: Agora Publicações, 2005.

VEZULLA, Juan Carlos. "Ser mediador - reflexões". In: Lígia Maia de Morais Sales (Org.). Estudos sobre a mediação e arbitragem., Rio - São PAULO - Fortaleza: ABC Editora, 2003.

WARAT, Luis Alberto. O ofício do mediador. Florianópolis: Habitus, 2001.

WATANABE, Kazuo. Cultura da sentença e cultura da pacificação. In: MORAES, Mauricio Zanoide; YARSHELL, Flávio Luiz (Coords.). Estudos em homenagem à professora Ada Pellegrini Grinover. São Paulo: DPJ, 2005.

Política pública do poder judiciário nacional para tratamento adequado dos conflitos de interesses. In: RICHA, Morgana de Almeida; PELUSO, Antonio Cezar (Coords.). Conciliação e mediação: estruturação da política judiciária nacional. Rio de Janeiro: Forense, 2011.

Revista de Formas Consensuais de Solução de Conflitos | e-ISSN: 2525-9679 | Belém | v. 5 | n. 2 | p. 01 - 19 | Jul/Dez. 2019. 